\title{
Health-related quality of life in laryngeal cancer patients
}

\author{
Larenks kanserli hastalarda sağlıkta yaşam kalitesi \\ Ercan Kaya, Cemal Cingi, Özgür Pınarbaşlı, Melek Kezban Gürbüz, Hamdi Çaklı, \\ Armağan İncesulu, Erkan Özüdoğru, Cem Keçik \\ Department of Otorhinolaryngology, Faculty of Medicine, Eskişehir Osmangazi University, Eskişehir, Turkey
}

\begin{abstract}
Objective: To compare health-related quality of life (QOL) in laryngeal cancer patients using generic and head and neck cancer-specific questionnaires.

Methods: A total of 52 patients, who were diagnosed as laryngeal cancer between January 2003 and January 2006, were included in the study. The patients were requested to fill up EORTC QLQ-C30 and EORTC QLQ-H\&N35 questionnaire forms. These questionnaires were responded by the patients before treatment and at 1st, $2 \mathrm{nd}, 3 \mathrm{rd}$, 6 th and 12 th months of the treatment.

Results: Patients who received surgical therapy or chemotherapy for laryngeal cancer without any tumor recurrence up to 12th month of the treatment were evaluated. Changes in the mean values of all variables other than the changes in the mean score of diarrhea variable of QLQC30 questionnaire were found to be statistically significant. The questionnaire scores of QLQ-H\&N35 were found to be statistically significant in terms of all variables except opening mouth, intake of nutritional supplements and use of feeding tube.

Conclusion: Since quality of life of the patients who had undergone functional surgery is more satisfactory, functional surgery should be preferred to the extent permitted by oncological principles.
\end{abstract}

Keywords: Quality of life, questionnaire, laryngeal cancer.

\section{Özet}

Amaç: Bu çalışmanın amacı larenks kanserli hastalarda sağlıkla ilgili yaşam kalitesini genel ve baş ve boyun kanserine özel anketler kullanılarak karşılaştırmaktır.

Yöntem: Ocak 2003 ve Ocak 2006 tarihleri arasında larenks kanseri tanısı alan 52 hasta çalışmaya dâhil edildi. Hastalardan EORTC QLQ-C30 ve EORTC QLQ-H\&N35 anket formları doldurmaları istendi. $\mathrm{Bu}$ anketler tedavi öncesi ve tedavi sonrası 1.,. 2. 3., 6., ve 12. aylarda dolduruldu.

Bulgular: Takiplerinin 12. ayına dek herhangi bir tümör nüksü gözlenmeyen ve cerrahi tedavi veya kemoterapi alan hastalar değerlendirildi. QLQ-C30 anket skorları, ishal değişkeni dışındaki tüm değişkenler açısından istatistiksel olarak anlamlı bulundu. QLQ-H\&N35 anket skorları, ağzını açma, besin takviyesi alımı ve besleme tüpü kullanımı dışındaki tüm değişkenler açısından istatistiksel olarak anlamlı bulundu.

Sonuç: Fonksiyonel cerrahi geçirmiş hastaların yaşam kalitesinin daha tatmin edici olması nedeniyle, onkolojik prensiplerin izin verdiği ölçüde fonksiyonel cerrahi tercih edilmelidir.

Anahtar sözcükler: Yaşam kalitesi, anket, larenks kanseri.
Health-related quality of life (QOL) is increasingly being recognized as an important issue in oncology. ${ }^{[1]} \mathrm{It}$ is a multidimensional concept which comprises four core domains: physical functioning, psychological functioning, social interaction and disease- and treatment-related symptoms. ${ }^{[2]}$ Quality of life is an important indicator of treatment outcome and is used increasingly as an end point in clinical trials. Patients with head and neck cancer not only have to face a life-threatening disease, they also have to deal with the impact of both the disease and its treatment on physical, psychological and social functioning. They are prone to psychosocial problems, because social interaction and emotional expression depend to a great extent upon the structural and functional integrity of the head and neck region. ${ }^{[3]}$
Correspondence: Ercan Kaya, MD. Department of Otorhinolaryngology, Eskisehir Osmangazi University Faculty of Medicine, Meselik Kampüsü, Eskişehir, Turkey.

e-mail: ercankayakbb@gmail.com

Received: February 18, 2014; Accepted: March 10, 2014; Published online: May 5, 2014
Online available at:

www.jmedupdates.org doi:10.2399/jmu.2014001007 QR code: 
Assessment of the impacts of head and neck cancer treatment requires specific tools, given the specific disorders of voice, swallowing and sensation as well as issues of physical appearance induced in these patients. QOL questionnaires are of two sorts: generic and specific. ${ }^{[4]}$ Generic tools assess the overall impact of health status, covering global functional dimensions such as the physical, social and psychological domains. Their drawback lies in their failure to spotlight particular aspects of certain pathological processes. Specific tools can compare patients with a given pathology and their sensitivity enables change in cancer patients' health status to be detailed over time.

The present study aimed to compare QOL in laryngeal cancer patients using generic and head and neck cancerspecific questionnaires.

\section{Materials and Methods}

Our study has been deemed appropriate with the Decree No. 26 dated 06.29.2006 of the Ethics Committee of Eskişehir Osmangazi University Faculty of Medicine. This study was performed in Eskişehir Osmangazi University, Faculty of Medicine between January 2003 and January 2006. Our study population consisted of 52 patients, who were diagnosed as laryngeal cancer based on histopathological examination of the biopsy materials, were included in the study. The patients were treated with surgery or chemoradiotherapy and attended their tumor control visits regularly without any evidence of recurrence up to post-treatment 12th month. The patients were divided into two main groups as for treatment modalities and those treated with surgical means were classified into two subgroups as those with or without tracheostomas (Table 1). The patients who had undergone neck dissection were classified in radical neck (RND) and functional neck dissection (FND) groups.

Basic demographic and clinical information of the patients (age, gender, occupation, marital status, educa- tional level of the patients, family members living in the same household, smoking, alcohol consumption, location, TNM and stage of the tumor, treatment applied, type of the surgical treatment (if any), speaking quality and medical history) were recorded.

During routine weekly controls of the tumor performed in our clinic, the patients who met the above criteria and whose routine controls were completed were provided with detailed information about the study. The patients who completed informative consent forms were requested to fill up the questionnaire forms namely Turkish version of EORTC QLQ-C30 Version 3.0 (European Organization for the Research and Treatment of Cancer Quality of Life Questionnaire) which consisted of two parts and Turkish version of EORTC QLQH\&N35 (European Organisation for Research and Treatment of Cancer, Questionnaire module to be used in Quality of Life assessments in Head and Neck Cancer). For permission to use these survey forms, we registered in Belgian Quality of Life Unit EORTC Data Center. ${ }^{[5]}$ These questionnaire forms were responded by the patients immediately before the treatment and at $1 \mathrm{st}, 2 \mathrm{nd}, 3 \mathrm{rd}, 6 \mathrm{th}$ and 12 th months of the treatment. At the evaluation periods, in other words at post-operative 1st, 2nd, 3rd, 6th and 12th months, total laryngectomized (TL) and near-total laryngectomized (NTL) patients had permanent tracheostomies, while hemilaryngectomized patients without tracheostomies or those receiving chemoradiotherapy had not tracheostomies.

Primary chemoradiotherapy protocol applied in laryngeal cancers was as follows:

\section{Primary Radiotherapy of the Supraglottic Region}

In T1N0-T2N0 tumors, using $6 \mathrm{MV} \mathrm{x}$-ray or cobalt-60 device, 66-70 Gy (2 Gy/day) was delivered to the primary tumor site and electively $50 \mathrm{~Gy}$ (2 Gy/day) to the cervical lymph nodes. In T3-4 (N+) tumors, 64-70 Gy was delivered

Table 1. Number and percentage of treated patients and type of treatment applied.

\begin{tabular}{|c|c|c|c|}
\hline \multicolumn{3}{|c|}{ Therapy applied } & \multirow{2}{*}{$\begin{array}{c}\text { n (\%) } \\
19(36.5 \%)\end{array}$} \\
\hline Surgery & Total laryngectomy & & \\
\hline & Near-total laryngectomy & & $5(9.6 \%)$ \\
\hline & Hemilaryngectomy without tracheotomy & $\begin{array}{l}\text { Cordectomy } \\
\text { Supraglottic HL }\end{array}$ & $\begin{array}{c}8(15.3 \%) \\
4(7.6 \%)\end{array}$ \\
\hline & & Vertical HL & $1(1.9 \%)$ \\
\hline & & Frontolateral HL & $1(1.9 \%)$ \\
\hline \multicolumn{2}{|c|}{ Chemoradiotherapy } & & $14(26.9 \%)$ \\
\hline
\end{tabular}

$\mathrm{HL}$ : hemilaryngectomy 
to the primary tumor site, while as a radiosensitizing agent for positive cervical lymph nodes, the patients received IV cisplatin at doses of $80 \mathrm{mg} / \mathrm{m}^{2}$ at 1st, 22nd and 43rd days of the radiotherapy. After administration of a dose of $44 \mathrm{~Gy}$, medulla spinalis was protected from radiation exposure.

\section{Primary Radiotherapy of the Glottic Region}

In T1-T2 N0 tumors, 66-70 Gy (2 Gy/day) was delivered locally only to the primary tumor site. However, in T3-4 and $\mathrm{N}+$ cases, 70 Gy was delivered to the tumor site, 50 Gy to the elective cervical lymph nodes and 64-70 Gy (2 $\mathrm{Gy} /$ day) to the affected lymph nodes (using 6- MV x- ray or cobalt-60 devices). In addition, to complete radiotherapy regimen, pathological lymph nodes localized at superoposterior aspect of medulla spinalis received 9-12 MeV electron beams. As a radiosensitizing agent, IV cisplatin at a dose of $80 \mathrm{mg} / \mathrm{m}^{2}$ was applied on $1 \mathrm{st}, 22 \mathrm{nd}$ and $43 \mathrm{rd}$ days of the radiotherapy. After administration of $44 \mathrm{~Gy}$, medulla spinalis was protected from radiation exposure.

\section{Quality of Life Assessment}

This consists of a generic section (QLQ-C30) comprising six functional scales (physical, social, emotional, cognitive, role and global health status), three symptom scales (fatigue, pain, nausea and vomiting) and six independent items (dyspnea, insomnia, appetite, constipation, diarrhea and financial difficulties). The specific head and neck cancer module (QOL-H\&N35) comprises seven symptom scales (pain, swallowing, senses, speech, social eating, social contact and sexuality) and nine independent items (teeth, opening mouth, dry mouth, thick saliva, cough, feeling ill, pain killers, nutritional supplements, feeding probe and weight gain and loss)..$^{[6-11]}$

\section{Statistical Evaluation}

Data were analyzed using SPSS (Statistical Package for Social Sciences; SPSS Inc., Chicago, IL, USA) 13.0, MINITAB 14 and Sigma Stat 6.0 statistical package programs. Comparisons between groups, radiotherapy application times, group- time interactions and also multiple comparisons were performed using repeated measures analysis of variance (rANOVA) method. For a single group, temporal comparisons were performed using twoway variance analysis (ANOVA).

\section{Results}

Fifty-two patients who received surgical therapy or chemotherapy for laryngeal cancer without any tumor recurrence up to 12 th month of the treatment were evaluat- ed. Study population with a mean age of 58 (range: 41 to 74 ) years consisted of $51(98.1 \%)$ male and one female $(1.9 \%)$ patients.

All of the patients were smoking an average of 25.46 [min. $2(3.8 \%)$ and max. $50(1.9 \%)]$ cigarettes a day for at least $5(1.9 \%)$ or at most $52(1.9 \%)$ (median: 32.25$)$ years. Twenty-two $(42.3 \%)$ patients did not use alcoholic beverages, while $28(53.8 \%)$ patients were using alcohol from time to time and $2(3.8 \%)$ patients were drinking alcohol every night. Patients were using alcohol for an average of 20.3 [min. 3 (1.9\%) and max. $30(1.4 \%)$ ] years.

Tumors were localized in the supraglottic $(n=20$; $38.5 \%)$, glottic $(\mathrm{n}=30 ; 57.7 \%)$ and subglottic $(\mathrm{n}=2 ; 3.8 \%)$ regions. According to TNM classification the patients were categorized as follows: $\mathrm{T} 1, \mathrm{n}=12$ (23.07\%); T2, $\mathrm{n}=14$ (26.92\%); T3, n=21 (40.38\%); T4, n=5 (9.61\%); N0, n=39 (75\%); N1, n=11 (21.2\%); N2, n=2 (3.8\%); M0, n=52 $(100 \%)$; Stages I, $\mathrm{n}=11$ (21.15\%); II, $\mathrm{n}=11$ (21.15\%); III, $\mathrm{n}=23(44.23 \%)$ and $\mathrm{IV}, \mathrm{n}=7(13.46 \%)$.

Our patients received surgical therapy $(\mathrm{n}=38 ; 73.1 \%)$ or chemoradiotherapy $(\mathrm{n}=14 ; 26.9 \%)$. As a surgical therapy the patients underwent total laryngectomy (TL) $(n=19 ; 36.5 \%)$, near-total laryngectomy (NTL) (n=14; $26.9 \%)$ and hemilaryngectomy without tracheotomy $(\mathrm{n}=14 ; 26.9 \%)$. During evaluation process, all of the partially laryngectomized patients were decannulated and their tracheostomas were closed. Techniques of partial laryngectomies included cordectomy $(n=8)$, supraglottic hemilaryngectomy $(n=4)$, vertical hemilaryngectomy $(\mathrm{n}=1)$ and frontolateral hemilaryngectomy ( $\mathrm{n}=1)$ (Table 1$)$.

As an adjunct to laryngeal surgery, unilateral radical neck dissection $(\mathrm{n}=17 ; 32.69 \%)$ and unilateral functional neck dissection ( $\mathrm{n}=2 ; 3.84 \%$ ) were performed. Besides, medical histories of 5 patients revealed the presence of significant diseases including hypertension $(\mathrm{n}=1)$, dilated cardiomyopathy $(n=1)$, coronary artery disease $(n=1)$ and chronic obstructive pulmonary disease $(n=2)$.

The patients could speak with the aid of a Bloom-Singer voice prosthesis $(\mathrm{n}=8 ; 15.4 \%)$, electrolarynx device (an artificial larynx device) $(\mathrm{n}=7 ; 13.5 \%)$ or using their esophageal voice $(n=4 ; 7.7 \%)$. The patients had a good $(n=25 ; 48.1 \%)$, moderate $(\mathrm{n}=23 ; 44.2 \%)$ and worse $(\mathrm{n}=3 ; 5.8 \%)$ voice qualities, while one patient $(1.9 \%)$ could not establish verbal communication with others.

In our study, the groups of surgery - chemoradiotherapy; hemilaryngectomy without tracheotomy - chemoradiotherapy; radical surgeries (TL+NTL) - hemilaryngectomy were compared between themselves and also with respect to changes in the post-operative quality of life with time. 
To evaluate the impact of neck dissection on the quality of life, patients who had undergone hemilaryngectomy without tracheotomy + radical neck dissection and those treated with only hemilaryngectomy without tracheotomy were compared between themselves and regarding changes in the post-operative quality of life with time.

In the QLQ-C30 questionnaire, changes in the mean score of diarrhea variable with time were not statistically significant ( $p>0.05)$. Changes in the mean values of all other variables of this questionnaire with time were found to be statistically significant $(\mathrm{p}<0.01$ and $\mathrm{p}<0.001$, respectively).

In the QLQ-H\&N35 module, changes in the mean values of opening mouth, intake of nutritional supplements and use of feeding tube with time were not statistically significantly different $(p>0.05)$. Changes in the mean values of all other variables of the QLQ-H\&N35 module with time were statistically significantly different $(\mathrm{p}<0.01$ and $\mathrm{p}<0.001$, respectively).

In the QLQ-C30 questionnaire, changes in the mean values of physical function, occupational activities, cognitive functioning, shortness of breath, financial difficulties with time were not statistically significantly different $(p>0.05)$. Changes in the mean values of all other variables of this questionnaire with time were statistically significantly different $(\mathrm{p}<0.05, \mathrm{p}<0.01$ and $\mathrm{p}<0.001$, respectively).

In the QLQ-H\&N35 module, changes in the mean scores related to decrease in sexuality, dry mouth, thick saliva, feeling ill, use of pain killers and nutritional supplements and weight gain with time were not statistically significant $(p>0.05)$. Changes in the mean scores of all other variables of the QLQ-H\&N35 module with time were statistically and extremely significant $(\mathrm{p}<0.05, \mathrm{p}<0.01$ and $\mathrm{p}<0.001$, respectively).

Changes in the mean scores related to the variables of constipation and diarrhea in the QLQ-C30 questionnaire with time were not statistically significantly different $(\mathrm{p}>0.05)$. Mean scores of the changes in all other variables of this questionnaire with time were found to be statistically significantly different $(\mathrm{p}<0.05, \mathrm{p}<0.01$ and $\mathrm{p}<0.001$, respectively).

Changes in the mean scores of the variables included in the QLQ-H\&N35 module such as opening mouth, intake of nutritional supplement, use of feeding tube, weight loss and weight gain with time were not statistically significant different $(p>0.05)$. Changes in the mean values of all other variables of the QLQ-H\&N35 module with time were statistically significantly and extremely different $(\mathrm{p}<0.05$, $\mathrm{p}<0.01$ and $\mathrm{p}<0.001$, respectively).

Changes in mean values of the variables of QLQ-C30 questionnaire, including global health state, emotional func- tion, social function, symptom scales, fatigue, sleeplessness, loss of appetite with time were statistically significant $(p<0.05, p<0.01$ and $p<0.001$, respectively). Changes in the mean values of all other variables of this questionnaire with time were not statistically significantly different $(\mathrm{p}>0.05)$.

In the QLQ-H\&N35 module, changes in the mean values of pain, speech difficulties, feeling sick with time were statistically significantly different $(\mathrm{p}<0.05$ and $\mathrm{p}<0.01$, respectively). Mean values of all other variables of the QLQ$\mathrm{H} \& \mathrm{~N} 35$ module with time were not statistically significantly different $(\mathrm{p}>0.05)$.

In none of the comparisons between surgery and chemoradiotherapy groups based on score variables of the QLQ-C30 questionnaire, any statistically significant difference was not found $(\mathrm{p}>0.05)$.

However, in the QLQ-H\&N35 module, a significant difference was detected in the score variables of sensory problems and dry mouth $(\mathrm{p}<0.01$ and $\mathrm{p}<0.05$, respectively). In both of these variables, mean score of the chemoradiotherapy group was higher than that of the surgery group.

In the QLQ-C30 questionnaire, mean score variables related to physical function, symptom scales, variables of nausea and vomiting and financial difficulties in the hemilaryngectomy with tracheostomy were statistically significantly different from those detected in the chemoradiotherapy groups $(p<0.05)$. Mean values for the physical function variable of the hemilaryngectomy without tracheotomy group were found to be higher than those of the chemoradiotherapy group. Mean values of symptom scales and variables as nausea, vomiting and financial difficulties in the chemoradiotherapy group were higher than those of the hemilaryngectomy without tracheotomy group.

In the QLQ-H\&N35 module, changes in the mean scores related to the variables of decreased sexuality, dry mouth and thick saliva were statistically significant different between hemilaryngectomy without tracheotomy and chemoradiotherapy groups $(\mathrm{p}<0.05)$. Mean values for all of these variables in the chemoradiotherapy group were found to be increased when compared with those of the hemilaryngectomy without tracheotomy group.

In the QLQ-C30 questionnaire, mean scores of variables related to functional scales, emotional function, cognitive function, social function and constipation were statistically significantly different between groups of hemilaryngectomy without tracheotomy and hemilaryngectomy without tracheotomy + radical neck dissection $(\mathrm{p}<0.05)$. Mean scores of the variables related to functional scales, emotional function, cognitive function and social function in the hemilaryngectomy without tracheotomy were found to be higher. Mean 
score of the constipation variable was higher in the hemilaryngectomy without tracheotomy + radical neck dissection group.

In the QLQ-H\&N35 module, with respect to mean scores of variables related to dental problems, use of pain killers, decrease in sexuality, a statistically significant difference was detected between hemilaryngectomy without tracheotomy and hemilaryngectomy without tracheotomy + radical neck dissection groups $(\mathrm{p}<0.05)$. Mean scores of these variables in the hemilaryngectomy without tracheotomy + radical neck dissection group were relatively higher.

In the QLQ-C30 questionnaire, mean values of the scores related to functional scales, physical function, occupational function, social function, symptom scales, fatigue, loss of appetite and constipation were statistically significantly different between groups of radical surgeries and hemilaryngectomies without tracheotomies. Mean scores of functional scales and variables such as physical and occupational function were higher in the group of hemilaryngectomy without tracheotomy, however in the group with radical surgeries mean values of the variables of social function, symptom scales, fatigue, loss of appetite and constipation were found to be relatively increased.

In the QLQ-H\&N35 module, mean scores of variables such as sensory problems, speaking difficulties, establishment of social relationship and dental problems changed statistically significantly with time. In the groups of radical surgeries mean values of these variables were relatively higher.

\section{Discussion}

The present study used the EORTC QoL questionnaire, comprising a generic (QLQ-30) and head and neck cancer-specific section (QLQ-H\&N35). Its validity and specificity have been demonstrated. Combined use of the two sections has been validated in a study of head and neck cancer patients in 12 countries: ${ }^{[1]}$ it was shown that the specific section provided information that the generic section could not assess.

In our study, our cases had glottic (57.7\%), supraglottic $(38.5 \%)$ and subglottic (3.8\%) tumors. In the study by Nordgren et al. ${ }^{[12]}$ glottic and supraglottic tumors were detected in $72.09 \%$ and $27.9 \%$ of their patients, respectively. In a study by Finizia et al. ${ }^{[13]}$ glottic $(64.2 \%)$, supraglottic $(21.4 \%)$, subglottic $(7.1 \%)$ and transglottic $(7.1 \%)$ cancers were detected in respective percentages. Weinstein et al. ${ }^{[14]}$ detected glottic and supraglottic cancers in 84 and $16 \%$ of their patients, respectively. As seen in the results of all these investigations, mostly glottic and rarely supraglottic cancers were encountered.
In our study, tumors of our patients were categorized according to TNM classification as: T1 (23.07\%); T2 (26.92\%); T3 (40.38\%) and T4 (9.61\%). In a study by Taş et al. ${ }^{[15]}$ nearly half of the tumors were T1-T2 and the other half was T3-T4. However, in a study by Finizia et al. ${ }^{[13]}$ tumors of the patients were classified as T1 (17.8\%); T2 (35.7\%); T3 (32.1\%) and T4 (14.2\%). Weinstein et al. ${ }^{[14]}$ reported tumors of their patients as $\mathrm{T} 1(6 \%)$; $\mathrm{T} 2$ (48\%), T3 (23\%) and T4 (23\%). Some diversities between the results of the researchers and ours stem from socioeconomical and cultural differences encountered in the country of investigation.

In our study, laryngeal cancer of our patients was at Stages I (21.15\%), II (21.15\%), III (44.23\%) and IV (13.46\%). Distribution of the patients based on the stages of laryngeal cancers as reported by some authors were as follows: Stages I (38.09\%), II (14.28\%), III (28.57\%) and IV $(19.0 \%)$ in the study of List et al.; ${ }^{[16]}$ Stages I (47\%), II (23\%), III (16\%) and IV (14\%) in the study of Hammerlid et al.: ${ }^{[17]}$ Stages I (17\%), II (25\%), III (35\%) and IV (23\%) in the study of Erdamar et al. ${ }^{[18]}$ Our results resemble those of obtained in the investigation performed by Erdamar et al. ${ }^{[18]}$ Since both of these surveys were performed in the population with similar socio-economical and cultural characteristics, similarities between their results are already anticipated.

Quality of life of our patients who underwent laryngeal cancer therapy increasingly improved from pretreatment levels up to 12th month of the follow-up period, however variables of diarrhea, opening mouth, intake of nutritional supplements, and use of feeding tube did not change with time. Hammerlid et al. ${ }^{[19]}$ followed up patients with head and neck cancers for three years and indicated an increase in the quality of life of the patients at the first post-operative months relative to the pretreatment values without any change in complaints including fatigue, nausea, vomiting and pain with time.

Quality of life decreases markedly during the postoperative period, and after the $3 \mathrm{rd}$ month, an adaptation process starts to take effect. From the 12th month on, the patient adapts to new living conditions, approaching to preoperative levels of QoL. ${ }^{[19-21]}$ In our study, QoL of the patients worsened during the first post-treatment month, started to improve from the 2 nd month on and climbed to upper levels at 12 th month. The study by Mercke et al. substantiates our findings. ${ }^{[17]}$

An improvement in the quality of life of our patients, who underwent surgical treatment requiring permanent stomas, was detected at the end of the follow-up period of 
one year. However, physical and occupational functions, financial difficulties, use of pain killers and complaints as decrease in sexuality and dry mouth did not change significantly during the follow-up period. This outcome has been anticipated for conditions where laryngeal preservation could not be achieved. Although during the first post-treatment months, speech problems worsened, decrease in these problems at 6 th and 12th months was a gratifying finding. Indeed, in many studies performed, speech has been emphasized as the most influential factor affecting quality of life. ${ }^{[13,15,18,22,23]}$

An unfavorable trend was seen in many quality of life variables of the patients during the first months after chemoradiotherapy, while at subsequent months, especially after 2 nd month, improvements in these variables were observed. Graeff et al. ${ }^{[24]}$ observed marked improvement in the post-treatment quality of life of laryngeal cancer patients followed up for one year after radiotherapy, but they could not detect marked improvement in complaints of thick saliva, sensory problems and dry mouth at 12 th month. However, on the contrary, in our study, at 12th month, improvement was detected in all of these symptoms. This phenomenon can be explained by differences in the application of chemoradiotherapy methods and our better radiotherapy regimen.

In a study performed by List et al. ${ }^{[16]}$ the authors detected that in hemilaryngectomized patients, speech and social eating problems had started to decrease from 6th week and 3rd month on, respectively. Also in our study, social eating and speech problems increased at first month after the treatment, but they decreased significantly in frequency at subsequent months.

Our first survey study, EORTC QLQ-C30 compared groups which received chemoradiotherapy or surgical treatment and could not find any significant difference between global health, functional and symptom scales. However, in our second survey study, EORTC QLQHN35 module, sensory (smell and taste) problems and complaints of dry mouth were more frequently encountered in the chemoradiotherapy group. In a study performed by Graeff et al. ${ }^{[2]}$ the authors reported persistence of problems and complaints as thick saliva, sensory problems and dry mouth. In a study performed by Müller et al. ${ }^{[23]}$ the researchers reported higher incidence of complaints as thick saliva and coughing in patients who received radiotherapy. Finizia et al. ${ }^{[13]}$ could not find any significant difference between total laryngectomy performed as salvage surgery and radiotherapy based on EORTC QLQ-C30 global health, functional and symp- tom scales; however, in the EORTC QLQ-HN35 module, hoarse voice was found to be significantly more frequent in the radiotherapy group. List et al. ${ }^{[16]}$ could not find any important difference in the quality of life scores of the patients who had undergone total laryngectomy, partial laryngectomy and radiotherapy based on PSS-HN (performance state scale for patients with head and/or neck cancers) and FACT-HN which is a multifaceted quality of life questionnaire.

In our survey, partially laryngectomized patients and those receiving chemoradiotherapy were compared in terms of quality of life and physical functions and these variables were found to be better in partially laryngectomized patients. Nausea and vomiting, decrease in sexuality, dry mouth, thick saliva and complaints of financial difficulties were more frequent in the patients receiving chemoradiotherapy. In a study performed by Schneider et al., ${ }^{[25]}$ the investigators compared patients who had been treated with $\mathrm{CO}_{2}$ laser surgery or radiotherapy regarding quality of life and detected that global health state had been improved in both treatment modalities, but they also indicated that difficulties in swallowing solid foods, dry mouth and dental problems were more frequently seen in patients who had received radiotherapy. Stoeckli et al. ${ }^{[20]}$ also compared $\mathrm{CO}_{2}$ laser surgery with radiotherapy as for quality of life and reported improved global health state in both groups. Still in this study, in the group of patients who received radiotherapy, financial difficulty symptom score was lower when compared with our study, but symptom scores related to dry mouth, difficulty in swallowing solid foods and dental problems were found to be increased. This phenomenon can be explained by the differences in social and epidemiological problems in countries of investigation.

In our study the impact of neck dissection on quality of life was investigated. As a result, compared with partially laryngectomized patients, in cases who had undergone partial laryngectomy combined with radical neck dissection, decreases in emotional, social functions, cognitive functioning, sexuality and frequency of constipation, while increases in analgesic use and dental problems were detected. Taş et al. ${ }^{[15]}$ obtained outcomes comparable to ours. In our study, increased analgesic use following neck dissection was in accordance with the findings of our literature review. Besides, in these studies, pain and shoulder dysfunction have been reported as the most important factors influential on the quality of life. ${ }^{[2,27]}$

Permanent tracheostoma is an application unwanted by the patients and it is one of the foremost reasons of 
declining surgical treatment. Still, in our study in cases with post-operative permanent tracheostomas (total and near-total laryngectomized patients), fatigue, constipation, appetite loss, sensory (smell and taste) disorders, speech, dental problems, and difficulties in establishing rapport with one's social environment were found to be worsened. However, it has been found that partially laryngectomized patients treated conservatively without permanent tracheostomas, had more frequently engaged in physical, social and occupational activities. Erdamar et al. ${ }^{[18]}$ using Washington University Quality of Life Inventory detected that near-total laryngectomy made a difference only in the evaluation of outer appearance when compared with other partial laryngectomies. Braz et al. ${ }^{[28]}$ compared patients who had undergone total or vertical partial laryngectomy with respect to quality of life and reported that they could not find any difference between both groups as for global health state with more improved social functions in the vertical partially laryngectomized group. They also indicated that in total laryngectomized patients, fatigue, social eating distress, financial difficulties and sensory disorders were more frequently encountered. Sewnaik et al. ${ }^{[2]}$ compared patients who had undergone partial or total laryngectomy because of failed radiotherapy with respect to quality of life, and as an outcome of their investigation, they emphasized that only sensory problems (impaired senses of smell and taste) were significantly deteriorated in total laryngectomized patients which lowered quality of life of the patient by decreasing the pleasure they derived from eating.

Supracricoid partial laryngectomy represents the extreme end of conservative techniques. Gregory et al. ${ }^{[14]}$ used SF-36 and Michigan Head and Neck Quality of Life questionnaire forms to compare the cases who had undergone this surgical technique or total laryngectomy. As an outcome of this survey, significantly better global health state, physical, social and emotional functions were detected in patients who had undergone supracricoid partial laryngectomy, while in total laryngectomized patients problems such as pain and difficulty in eating were more frequently reported. Müller et al. ${ }^{[23]}$ emphasized that quality of life of the patients who had undergone total laryngectomy was worse than that of the patients treated conservatively. Besides, in parallel with our study, they detected deterioration in daily life activities and social functions, difficulties in establishing rapport with one's social environment, decrease in sexuality and financial difficulties in these patients. Stage of the tumor at the time of diagnosis is the most important factor in the decision-making process for treatment modality. Hammerlid et al. ${ }^{[17]}$ found out that quality of life of the cases with advanced stage tumors was affected more adversely after termination of the treatment. Therefore, we think that quality of life surveys comparing treatment methods applied for the patients at the same stage of their disease will provide us more objective information.

Müller et al. ${ }^{[23]}$ reported that though effective speaking voice is an important personal characteristics and one of the fundamental factors influencing quality of life, EORTC QLQ-H\&N35 questionnaire survey had proved its inadequacy in disclosing its impact on QoL. However, based on our study, we think that since in cases which larynx could not be protected from injury, speech disorders and difficulty in establishing rapport with one's social environment worsen, the questionnaire in question actually does not fail to characterize this impact.

\section{Conclusion}

Since quality of life of the patients who had undergone functional surgery is more satisfactory, functional surgery should be preferred to the extent permitted by oncological principles. We think that as an outcome of multicentered, larger- scale, long-term studies with similar design conducted with patients at the same stage of the disease but under different treatment alternatives, the quality of life of the patients will improve at a greater extent.

\section{Acknowledgement}

We would like to thank our supervisor Prof. Emre Cingi, MD, who passed away in June 2012, for his support through this research.

Conflict of Interest: No conflicts declared.

\section{References}

1. Fung K, Lyden TH, Lee J, et al. Voice and swallowing outcomes of an organ-preservation trial for advanced laryngeal cancer. Int J Radiat Oncol Biol Physiol 2005;63:1395-9.

2. Aaronson NK, Bullinger M, Ahmedzai S. A modular approach to quality-of-life assessment in cancer clinical trials. Recent Results Cancer Res 1988;111:231-49.

3. Breitbart W, Holland J. Psychosocial aspects of head and neck cancer. Semin Oncol 1988;15:61-9.

4. Hanna E, Sherman A, Cash D, et al. Quality of life for patients following total laryngectomy vs chemoradiation for laryngeal preservation. Arch Otolaryngol Head Neck Surg 2004;130:8759. 
5. QL Coordinator Quality of Life Unit, EORTC Data Center, Avenue E Mounier 83 - B11, 1200 Brussels, Belgium. Email: abo@eortc.be

6. Bjordal K, de Graeff A, Fayers PM, et al. A 12 country field study of the EORTC QLQ-C30 (version 3,0) and the head and neck cancer specific module (EORTC QLQ-H\&N35) in head and neck patients. EORTC Quality of Life Group. Eur J Cancer 2000; 36:1796-807.

7. Guzelant A, Goksel T, Ozkok S, Tasbakan S, Aysan T, Bottomley A. The European Organization for Research and Treatment of Cancer QLQ-C30: an examination into the cultural validity and reliability of the Turkish version of the EORTC QLQ-C30. Eur J Cancer Care (Engl) 2004;13:135-44.

8. Bjordal K, Ahlner EM, Tolleson et al. Development of a European Organization for research and Treatment of Cancer (EORTC) questionnaire module to be used in quality of life assessments in head and neck cancer. Acta Oncol 1994;33:879-85.

9. Bjordal K, Hammerlid E, Ahlner EM et al. Quality of life in head and neck patients: validation of the EORTC H\&N35.J Clin Oncol 1999;17:1008-19.

10. Sherman AC, Simonton S, Adams DC, Vural E, Owens B, Hanna E. Assessing quality of life in patients with head and neck cancer: cross-validation of the European Organization for Research and Treatment of Cancer (EORTC) Quality of Life Head and Neck module (QLQ-H\&amp;N35). Arch Otolaryngol Head Neck Surg 2000;126:459-67.

11. Bjordal K, de Graeff A, Fayers PM, et al. A 12 country field study of the EORTC QLQ-C30 (version 3.0) and the head and neck cancer specific module (EORTC QLQ-H\&N35) in head and neck patients. EORTC Quality of Life Group. Eur J Cancer 2000; 36:1796-807.

12. Nordgren M, Abendstein H, Jannert M, et al. Health-related quality of life five years after diagnosis of laryngeal carcinoma. Int J Radiat Oncol Biol Phys 2003;56:1333-43.

13. Finizia C, Hammerlid E, Westin T, Lindstrom J. Quality of life and voice in patients with laryngeal carcinoma: a posttreatment comparison of laryngectomy (salvage surgery) versus radiotherapy. Laryngoscope 1998;108:1566-73.

14. Weinstein GS, El-Sawy MM, Ruiz C, et al. Laryngeal preservation with supracricoid partial laryngectomy results in improved quality of life when compared with total laryngectomy. Laryngoscope 2001;111:191-9.

15. Taş A, Yağız R, Karasalihoglu AR, Koten M, Adalı MK, Uzun C. Assessment of quality of life in patients with laryngeal cancer after surgical treatment. [Article in Turkish] Kulak Burun Bogaz Ihtis Derg 2004;12:84-90.
16. List MA, Ritter-Sterr CA, Baker TM, Colangelo LA, Matz G, Pauloski BR, Logemann JA. Longitudinal assessment of quality of life in laryngeal cancer patients. Head Neck 1996;18:1-10.

17. Hammerlid E, Mercke C, Sullivan M, Westin T. A prospective quality of life study of patients with laryngeal carcinoma by tumor stage and different radiation therapy schedules. Laryngoscope 1998;108:747-59.

18. Erdamar B, Süoğlu Y, Kıyak E, Sunay T, Katırcıoğlu S, Güven M, Akdağ K. Cerrahi tedavi uygulanan larenks kanserli hastaların uzun dönemde yaşam kalitelerinin değerlendirilmesi. Kulak Burun Bogaz Ihtis Derg 2001;8:219-25.

19. Hammerlid E, Silander E, Hornestam L, Sullivan M. Healthrelated quality of life three years after diagnosis of head and neck cancer-a longitudinal study. Head Neck 2001;23:113-25.

20. Stoeckli SJ, Guidicelli M, Schneider A, Huber A, Schmid S. Quality of life after treatment for early laryngeal carcinoma. Eur Arch Otorhinolaryngol 2001;258:96-9.

21. Hammerlid E, Bjordal K, Ahlner-Elmqvist M, et al. A prospective study of quality of life in head and neck cancer patients. Part I: at diagnosis. Laryngoscope 2001;111(4 Pt 1):669-80.

22. DeSanto LW, Olsen KD, Perry WC, Rohe DE, Keith RL. Quality of life after surgical treatment of cancer of the larynx. Ann Otol Rhinol Laryngol 1995;104(10 Pt 1):763-9.

23. Muller R, Paneff J, Kollner V, Koch R. Quality of life of patients with laryngeal carcinoma: a post-treatment study. Eur Arch Otorhinolaryngol 2001;258:276-80.

24. de Graeff A, de Leeuw RJ, Ros WJ, et al. A prospective study on quality of life of laryngeal cancer patients treated with radiotherapy. Head Neck 1999;21:291-6.

25. Schneider A, Guidicelli M, Stockli SJ. Quality of life after treatment of laryngeal carcinoma: surgery versus radiotherapy. Schweiz Med Wochenschr Suppl 2000;116:31S-34S.

26. Kuntz AL, Weymuller EA Jr. Impact of neck dissection on qualty of life. Laryngoscope 1999;109:1334-8.

27. Terrell JE, Welsh DE, Bradford CR, et al. Pain, quality of life and spinal accessory nerve status after neck dissection. Laryngoscope 2000;110:620-6.

28. Braz DS, Ribas MM, Dedivitis RA, Nishimoto IN, Barros AP. Quality of life and depression in patients undergoing total and partial laryngectomy. Clinics (Sao Paulo) 2005;60:135-42.

29. Sewnaik A, Van Den Brink JL, Wieringa MH, Meeuwis CA, Kerrebijn JD. Surgery for recurrent laryngeal carcinoma after radiotherapy: partial laryngectomy or total laryngectomy for a better quality of life? Otolaryngol Head Neck Surg 2005;132:958 .

This is an open access article distributed under the terms of the Creative Commons Attribution-NonCommercial-NoDerivs 3.0 Unported (CC BYNC-ND3.0) Licence (http://creativecommons.org/licenses/by-nc-nd/3.0/) which permits unrestricted noncommercial use, distribution, and reproduction in any medium, provided the original work is properly cited.

Please cite this article as: Kaya E, Cingi C, Pınarbaşlı Ö, Gürbüz MK, Çaklı H, İncesulu A, Özüdoğru E, Keçik C. Health-related quality of life in laryngeal cancer patients. J Med Updates 2014;4(1):29-36. 